\title{
Problems and Countermeasures in Construction Engineering Quality Management
}

\author{
Dongfang Fu \\ Guiyang Water Resources and Transportation Development Investment Group Co., Ltd., Guiyang Guizhou, \\ 550003, China
}

Keywords: Construction engineering, Quality management, Problem, Countermeasure.

\begin{abstract}
The quality of construction projects requires the effective implementation of construction work and management work, prompting the realization of overall functions of buildings and ensuring the positive development of work. In order to manage the quality of construction projects, we need to improve in all aspects, including not only the design and construction, but also the optimization of personnel and systems. To ensure the full implementation of construction quality management, so as to enhance the quality of the project. Therefore, in the article, through the relevant cases and construction project quality management understanding, analysis of construction project management issues, to ensure that they put forward more effective implementation countermeasures.
\end{abstract}

\section{Introduction}

With the improvement of the economic level of the modern society, our country can improve and reform to ensure the positive development and construction of the construction industry. However, during the construction of the construction project, some quality problems will also occur, causing great losses to people's lives and property and affecting the overall safety. Therefore, to do a good job of quality management of construction projects to ensure the implementation of its significance.

\section{Construction Engineering Quality Management}

With the gradual improvement of modern economic and social standards, our country has been able to develop. The construction industry also achieved rapid progress. However, there are still some problems in the actual construction management and construction work. Especially in the industry gradually expanded, causing construction quality problems, to people's lives and property safety also caused greater losses. Therefore, in today's fiercely competitive market, in order to improve the overall quality of construction projects, effective supervision needs to be put in place to ensure the positive development of the construction industry. In view of the existence of the quality problems of the construction project, the author studies the pertinent problems and takes the construction work as the basic condition to ensure the safety of the whole building. In view of its existing quality problems, it is necessary to summarize the experience in the construction project and analyze its existing problems. In the construction work and design work, it is necessary to ensure the rationality of the construction drawings and provide an effective guarantee for its development.

\section{Case Analysis}

A national highway is part of the reconstruction project. The west exit and the east of the tunnel are 450 meters in length, with a total length of 1348 meters. The project tunnel is a cross-mountain rock tunnel. The whole site has a large topography. The lowest elevation at the tunnel entrance is 210 meters and the highest is 375 meters. The relative height difference is 165 meters. The whole structure is low-mountain erosion landscape. According to the survey and analysis, there are obvious quality problems in construction projects, and if not actively controlled, it will cause great risks to the project. Therefore, in the following, in view of the quality management of construction engineering, 
analyze its existing problems and put forward effective countermeasures for each problem so as to ensure that it can control the construction quality of construction projects as a whole and also provide effective protection for the whole project.

\section{The Existing Construction Quality Management Problems}

\subsection{Design Problems}

In the construction and development of the project, due to the relatively small number of designers and participants, it is impossible to participate in the design work and affect the positive development of the inspection work. When the design work is completed, the design and implementation of the trial plans are not strict, only to achieve the safety inspection of work processes, structures and other aspects of work, do not attach importance to the inspection of ancillary structures and other projects. Meanwhile, in the design work, its existing problems will also affect the project investment work and the quality work, which cannot prompt its positive development. When the construction work, it will also find some problems, the improvement of the cost is relatively low, cannot be raised to correct the problem, resulting in increased costs of work. For example: a project for the tunnel situation. During the construction period, it was found that the design problems in construction management are even more serious. Such as: no analysis of each building, will lead to construction work, maintenance and management work to face greater difficulties. At the same time, there is also no gate to access platforms such as maintenance platforms in various construction areas, resulting in incomplete materials and equipment used in the future and difficulties in site construction. For the tunnel construction, nor the design of construction drawings, but the use of concrete structures or waterproof mortar, etc., in order to achieve effective waterproofing. For concrete pouring, plastering mortar and other construction quality cannot be guaranteed, will lead to wall area seepage and produce moisture and so on.

\subsection{Construction Problems}

Firstly, the existence of management mechanism issues. In the construction and management of work, people are the main part. However, in modern corporate construction work, many managers are employed outside or migrant workers. In order to reduce labor costs in project development, reduce project management, cannot guarantee the soundness of the regulatory agencies. At the same time, with more pressure on staff, most of the construction projects tend to be formalized with serious defects in their management functions. Migrant workers affected by the education level, only the implementation of manual labor, the technical requirements of unreasonable, cannot guarantee the overall quality and safety of the project. Irrational construction workers, etc., will also affect the efficiency of construction enterprises and reduce the overall construction quality of the project.

Secondly, the quality of materials and equipment. Construction materials used in the work, equipment, etc. will affect the overall construction quality. However, if the materials and equipment used fail to meet the construction standards in construction, the construction quality of the project will be affected, and obvious construction costs and construction periods will also be incurred. Construction enterprises did not attach importance to the accumulation of business operations, there is a serious shortage of funds, and construction work cannot be achieved supporting the development, affecting the quality of construction work. For material work, it is mainly because of the lack of management system in the enterprise. In the whole, there is obviously not strict work and cannot be effectively implemented in accordance with reasonable regulations, thus reducing the construction quality of the project. Such as: a tunnel reconstruction project construction and development, the quality of unqualified commercial concrete, resulting in the demolition of buildings, resulting in serious economic losses, affecting the project duration [1].

Thirdly, excessive emphasis is put on completion according to time, thus affecting the overall construction quality of the project. In the course of construction and development of a tunnel project, the construction period faced by the project is even more intense. In order to reach the construction period and ensure that the construction is completed within a reasonable time, the construction unit 
will construct the construction link in advance and fail to comply with certain technical requirements and regulations Implementation, nor the overall construction process of scientific management, thus affecting the overall project control. During the construction of various engineering sectors, the quality of the subprojects is poor and the construction process is unreasonable, causing various problems, thus affecting the overall quality of construction projects.

\subsection{Mechanism Problems}

Supervision mechanism is not perfect, the staff's own quality and low level of comprehensiveness. In the construction and development of tunnel engineering, despite the presence of supervisors, effective supervision of the construction process has been implemented. However, some supervisors lack their own experience, have lower comprehensive qualifications, have legal awareness, and have a weak sense of contract ideology. They cannot guarantee the realization of the role of supervision. In addition, the tunnel construction work is based on the whole process of planning, design and construction, and needs to be supervised in various aspects. However, in practical work, only emphasis is placed on the quality supervision and acceptance of construction sites and the lack of accounting standards for construction projects. In all aspects of the implementation of the way, but also its quality control, resulting in the problem cannot be effectively resolved.

Therefore, based on the existence and emergence of each of the above problems, it is necessary to put forward more reasonable implementation measures for them. Promote the implementation of design work, construction work and personnel supervision and control of all aspects of its existence, so as not only to ensure the overall quality of the project, but also for the positive development of construction projects to provide protection [2].

\section{Solutions to the Problems of Quality Management in Construction Engineering}

\subsection{Improve the Quality of Design Work}

Intensify the implementation of design work, the need for detailed design of construction drawings in the work, to avoid formalization, so as not to work in the construction and operation management, resulting in obvious design problems. If the existence of the design problem is relatively simple to deal with, the economic loss caused is also relatively small. Such as: the design drawings problems, will bring more serious economic losses, but also lead to a lot of manpower and material resources, resulting in more serious construction accidents [3]. Therefore, to solve all the problems encountered in the design work to ensure the overall quality of work, to maintain the overall development effectiveness.

\subsection{Strengthen the Construction Quality Management}

Firstly, actively manage the construction team. In order to improve the overall technical and professional level of constructors and managers and improve the overall quality of construction projects, it is necessary to formulate a sound system of manager responsibility for them. In the work, it is necessary to focus on employing those who have a high sense of responsibility, a strong organizational capacity and a higher level of construction technology. They need to understand the relevant laws and regulations. For the project manager, in the actual work, the need for full authorization, and according to the implementation of the project requirements, departments and positions set. But also to hire more suitable construction technicians to ensure that the full responsibility of the job responsibilities and promote the full development of individuals to ensure that in a comprehensive manner to enable professional managers and general staff to participate in on-site management. It also needs to be based on the actual construction requirements of the project, to co-ordinate and optimize them, to ensure the balance of post settings, to avoid a lot of waste of human resources. Based on a complete implementation plan, it is guaranteed that the staffing status can be redeployed to promote the enthusiasm and initiative of staff members. Such personnel's own functions are not only given full play, but also to achieve stable and efficient production efficiency. But also train the technical staff to guide them to achieve safety in production, especially for migrant 
workers. They also need to train their work safety and their own skills so as to ensure that staff can fully grasp the construction techniques and promote the effective improvement of work standards. In the actual construction work, we also need to enhance the awareness of quality and fully implement the work system so as to ensure the all-round progress and development of construction management.

Secondly, manage the quality of equipment, materials and products. In the actual implementation process, we need to improve in three aspects. First of all, quality control in the early construction [4]. In actual work, we need to test the quantity and frequency of material entering according to strict requirements and regulations. When the discovery of substandard materials, it is necessary to clean up, cannot be used to ensure that the equipment entered can meet certain technical requirements. Then, to control the construction process, in order to conduct a comprehensive quality control of the construction process, need to do a good job in acceptance. Such as: intermediate products, sub-projects, the quality of sub-divisions, need to achieve effective assessment and acceptance, to ensure that within certain provisions, to promote the accurate implementation of construction work. Finally, the latter part of the control work, the completion of the quality inspection. During the actual work, the unit needs to evaluate the quality of the project, review the project quality documents therein and promote the active implementation and effective development of the filing work. When implementing quality management throughout the process, quality control is based on the ISO 9000 system. According to certain goals in the work, to achieve the layered, cyclic options, but also to build a set of perfect quality management system in line with the characteristics of project construction. Moreover, it is necessary to analyze all the problems that exist in time and ensure that it can be resolved in time. In the work, we can focus on building a quality management team to transform production-based management into a management-oriented one so as to promote the quality of construction projects [5].

Thirdly, to strengthen the management of construction period. According to the requirements of the contract, to develop an effective plan to ensure that plans can be identified, but also for the construction of the construction schedule, network map, etc., to ensure that in the construction work, the progress of the project in a timely manner to check, but also in accordance with A certain progress, to promote the realization of the network map. For the deviation of its existence, but also to find the reasons for its existence, and propose a more reasonable solution. When checking the construction period, we also need to realize quality control and investment control according to the actual situation. Such as: construction work in the monitoring work, and in accordance with the construction period, promised to be carried out in accordance with a certain order, nor free to compress the construction period to promote the quality of construction projects.

\subsection{Play a Supervisory Role}

In order to give full play to the role of supervisors, we should do two aspects of work in a fundamental sense. First, to strengthen the supervision system. In the supervision work, it is necessary to supervise the whole process based on the planning and design, and ensure the positive development and implementation of the construction work. Second, to improve the professional quality of supervision staff, in the construction of the project, we should employ highly competent and experienced management personnel and supervise the construction work. Also need to set up high-quality personnel for its team to ensure the role of supervision work. But also based on service work, to change, to promote the role of supervision work. Also need to civil engineering construction, design work to achieve all-round supervision, to ensure that staff and owners, construction units and other functions effectively achieved, but also for the overall construction project to provide protection.

\section{Conclusions}

Based on the above analysis and research, it is found that to ensure the positive development of construction project quality management, it needs to be improved in terms of design, construction and supervision. We must also strengthen the system construction and promote the stable implementation of the work measures. At the same time, it will ensure that the technical level of staff members and 
their own ability to enhance and deepen into the specific production work, and as a basic condition of work, so that it cannot only demonstrate the effective implementation of its overall work, but also to ensure the safety of the project.

\section{References}

[1] Huang Cenggang. Housing Construction Quality Management Problems and Countermeasures, Jiangxi Building Materials, 2013 (4): 119-120.

[2] Fang Haiquan, Wang Rui. Quality Management Problems and Countermeasures of Construction Projects, Value Engineering, 2011, 30 (30): 53.

[3] Huang Bo. Construction Quality Management of Housing Construction Problems and Countermeasures, Talent Chi, 2011 (10): 30.

[4] Guo Jingjing. How to Improve the Quality of Construction Management, Doors and Windows, 2016 (11): 70.

[5] Lin Haishan. Problems and Countermeasures of Quality Management during Construction Stage of Construction Project, Building, Building Materials \& Decoration, 2015 (17): 198-198,200. 